\title{
The Characteristic Analysis of Emergency Logistics Vehicle Scheduling Problem and the System Design
}

\author{
Ruiwei Liang \\ Hunan Modern Logistics College \\ Changsha, China 410131
}

\author{
ShijunYuan* \\ Hunan Modern Logistics College \\ Changsha, China 410131 \\ *Corresponding Author
}

\begin{abstract}
How to schedule emergency logistics vehicles has become a significant issue studied for logistics and traffic. Based on characteristics of emergency logistics, this article shows the difference between emergency logistics and general vehicles scheduling, designing an emergency logistics vehicle scheduling system. In the end, it reveals key problems existing in the emergency logistics vehicle scheduling system.
\end{abstract}

Keywords-emergency logistics; vehicle scheduling; system design

\section{INTRODUCTION}

Emergency logistics refers to a special logistics arrangement [1] against emergencies such as severe natural disasters, unexpected public health accidents, security accidents or military conflicts in order to protect materials, personnel and capital. Seen from a wide range, the emergency logistics should cover logistics arrangements which are more urgent than normal ones in production, service, information and safety in order to meet special demands. The emergency logistics shall include products-related access, transport, storage, loading and unloading, packaging, distribution and information process.

\section{LITERATURE REVIEW}

Heung-suk[2] proposes a distribution model to create distribution plans related to disaster relief materials; He Jianmin, etc [3] analyzes the optimization of relief places for relief materials, creating an objective function to minimize transport and supply stations for a mathematical model, and adopts fuzzy optimization method to solve. Gao Hui[4] analyzes how to schedule emergency vehicles in a thesis for master's degree, based on rational assumptions, an emergency vehicle scheduling mode is created targeting the failure to meet minimize materials within a required time at a supply station, and the time of emergency logistics is embodied via divided time periods. Chen Jie[5] considers the randomness of vehicle arrangement and limited time limit when needed, creating an emergency vehicle scheduling mathematical model targeting the failure to supply adequate disaster relief materials to minimize the loss. Miu Cheng[6] adopts a flat structure designing emergency logistics center, materials transfer site for starting emergency logistics and emergency logistics supply network at demand center. Based on considering more supply sites, demand sites and transport modes network, a model integrating material transport and vehicle scheduling is created, and design a transport scheduling algorithm to solve on the basis of Lagrangean relaxation method.

Considering factors as time, costs and environmental influence, Ji Lei[7] creates a multi-purpose model for disaster relief materials transport, giving a general account for such goals. Shi Youlin[32] creates a multi-purpose integer and multi-goods time network model for road repairs after disaster as well as a time network for disaster relief materials transport.

Seen from literatures mentioned above, some scholars overseas have conducted pioneering researches on emergency materials transport and vehicle scheduling. However, domestic experts just raises concept of the emergency logistics, and the emergency materials transport and vehicle scheduling are just at the beginning.

\section{EMERGENCY LOGISTICS CHARACTERISTICS}

General logistics arrangements focus on logistics efficiency and benefits, yet in most cases, the emergency logistics just achieves the benefits via high logistics efficiency. Generally the emergency logistics have characteristics as sudden, uncertain, urgent, low-economic and unusual.

\section{A. Sudden and Diverse}

To be sudden and diverse is an obvious characteristic to distinguish it from general logistics. Generally it is very difficult for us to predict what will happen such as natural disasters. Due to the high time validity of emergency logistics, it must be achieved within a given time at the rapidest speed via a most safe method.

\section{B. Uncertain}

Due to uncertain sudden accidents, it is hard for us to predict how long the sudden accident will last, how it will influence and expand; therefore, the emergency logistics just vary with it.

\section{Urgent Need}

It is known to us that after a sudden accident happens, a high demand for foods, cotton quilts, drugs and result tools will arise in a short time, which needs a quick response emergency rescue system and efficient purchase system. 


\section{Low-economic}

Main characteristic of emergency logistics is emergency, so we cannot arrange logistics activities as usual; otherwise, it will be unable to meet the urgent demands for logistics.

\section{E. Unusual}

For the emergency logistics are special and urgent which makes it completely different from general ones, and many links that exist in usual logistics arrangements will be neglected in order to keep the emergency logistics urgent and simplified, so it is done under being strongly unusual or political.

\section{DistingUISHING EMERGENCY LOGISTICS FROM USUAL VEHICLE SCHEDULING}

According to what we have shown above, the emergency logistics is sudden, uncertain, urgent, unusual and loweconomic, therefore, the emergency vehicle scheduling, an important link in logistics must be highly different from usual vehicle scheduling (or transport ways):

- Different goals: since the emergency logistics is special and low-economic, the benefit principle for usual logistics arrangements shall not be considered as goals, and the emergency vehicle scheduling is to achieve how to minimize the transport time and costs, aimed at transporting disaster relief materials to the disaster regions as possible as we can and efficiently whiling minimizing the whole transport costs.

- For the emergency logistics is sudden and uncertain, the kinds and number of relevant materials are uncertain, besides, the materials supply and demand vary with the time; in addition, the emergency logistics is to meet the demands for materials at disaster regions as possible as we can, generally, many supply stations are set for materials distribution. Yet the supply, demand and quantity of vehicles for usual vehicle scheduling are certain, which generally has one supply station.

- The vehicles used for emergency logistics are generally taken over by authorities from social groups or individuals temporarily, which will arise at any site of the transport network. Besides, after completing the transport, the vehicles may not return where they come from, just waiting for a new task at where they reach, and then start the next transport to a new supply site. Yet general vehicle scheduling has fixed supply and demand sites, and the vehicles will return where they come from after completing the transport.

The special arrangements for emergency vehicle scheduling determines its differences from general vehicle scheduling, for example, in order to accelerate the transport, the emergency vehicle scheduling may adopt multiple methods, yet general vehicle scheduling mainly relies on single transport mode.

\section{EMERGENCY LOGISTICS SCHEDULING SYSTEM DESIGN}

The emergency logistics scheduling system design is given as follows: 


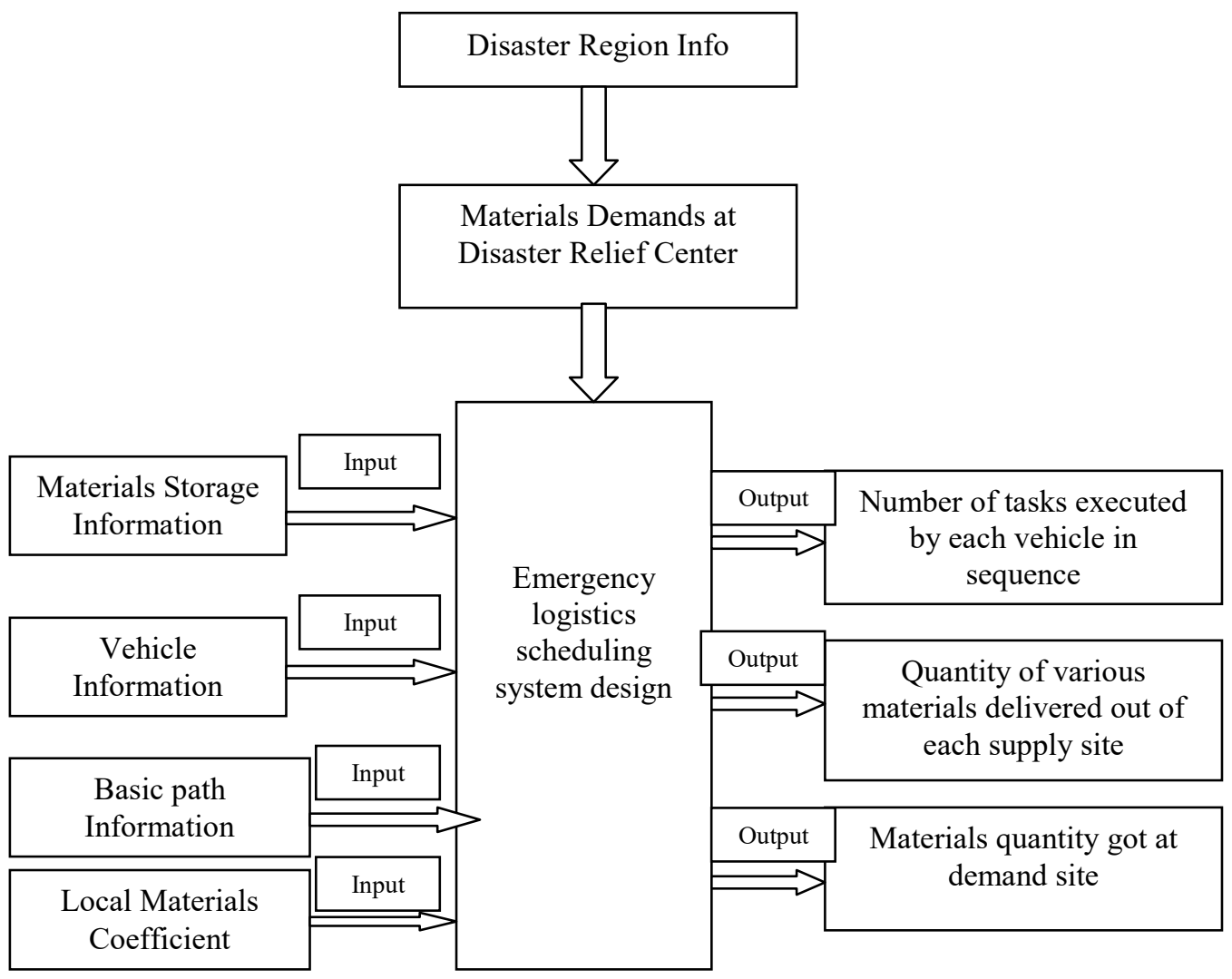

Fig. 1. Emergency logistics scheduling system.

\section{A. System Input}

Including information as follows:

- Disaster data: including total population, homeless people, the injured, area coefficient, seasonal coefficient and more. According to the information, we can get the materials demands at disaster relief center;

- Materials storage data: including diverse materials stored or collected at the materials storage center, as well as unit mass and volume of each material;

- Vehicle data: including loading, capacity, driving speed and initial site;

- Way data: the shortest distance from the materials storage center to disaster relief centers;

- Punishment coefficient for each material failed to meet.

\section{B. Output}

Main information output includes:

- Vehicle tasks: Completed tasks, transport site and destination, material kinds and disaster relief centers;

- Materials quantity distributed from storage centers;

- Materials quantity meeting needs at disaster relief centers.

\section{KEY PROBLEMS EXISTING IN THE EMERGENCY LOGistics VeHICLE SCHEDULING SySTEM}

\section{A. Calculation on Demands for Materials at Disaster Relief Centers}

Disasters vary with demands for materials and kinds. For example, when earthquake hits, our rescue is a significant measure to reduce the post-disaster loss at the disaster areas, yet, it generally will need a long time to get what the disaster areas need. After the earthquake happens, generally we can only get information such as site, scope, death toll, the injured, the homeless, house collapse and roads destroy and more, which will be used as basis for decision making when considering what the disaster areas need.

According to the earthquakes in the past, we can see that even the loss is the same in an earthquake, the people and materials arranged for disaster relief vary with areas, and more resources are provided to bigger cities and developed areas by authorities and social fields, because the bigger cities and developed areas should main tasks for national economic development, besides, with a large population, it will have a high influence in politics and economy, so the disaster areas must be restored quickly and avoid its adverse influence to areas round and the nation. Just based on such consideration, when researching and designing the concept model, we borrow a concept as area coefficient. Researches have shown that after earthquake the materials different areas receive and personnel support are obviously related to the economic development 
level, population distribution, namely the area coefficient is related to the population density and economic level[40][41]. For earthquake may happen at any season, yet the demands for disaster relief materials vary with seasons, especially the materials related to the people's living greatly change with seasons, so the coefficient season is borrowed.

Important materials quantity needed at earthquake:

Tent $($ piece $)=0.25 \mathrm{x}$ the homeless $\mathrm{x}$ season coefficient

Drinking $(\mathrm{kg})=$ area coefficient $\times 2 \times$ total population in disaster $\mathrm{x} 10 \mathrm{~d}$

Stretcher $($ piece $)=$ area coefficient $\mathrm{x} 0.08 \times$ the injured

Blood for operation $(\mathrm{ml})=50 \times$ the injured

Bed $($ piece $)=$ area coefficient $\times 0.215 \times$ the injured

Grain $(\mathrm{kg})=$ area coefficient $\mathrm{x}(5.7 \mathrm{x}$ the injured $+1.6 \mathrm{x}$ total population in disaster)

Clothes $($ piece $)=$ area coefficient $\mathrm{x}(6.8 \mathrm{x}$ the injured + $2.156 \times$ total population in disaster)

Cotton quilt $($ bed $)=$ area coefficient $\times 0.004 \times$ total population in disaster $\mathrm{x}$ disaster coefficient

Cotton clothe $($ set $)=$ area coefficient $\times 0.27 \times$ total population in disaster $\mathrm{x}$ season coefficient

Shoes (pair) =area coefficient $\mathrm{x} 0.79 \times$ the injured $+0.2 \mathrm{x}$ total population in disaster $\mathrm{x}$ disaster coefficient)

Movable toilet $=0.02 \mathrm{x}$ total population in disaster $\mathrm{x}$ disaster coefficient

Socks, shoes, towel and cups $=$ area coefficient $\times 12.9 \times$ the injured $+1 \mathrm{x}$ total population in disaster $\mathrm{x}$ disaster coefficient

According to formula mentioned above, we can get the materials demand at disaster relief centers after earthquake happens. If other sudden disasters happen, we can also get the materials demand at disaster relief centers according to the population in disaster, the homeless, the injured and the materials related formula.

\section{B. The Shortest Way from Materials Storage Centers to Disaster Relief Centers}

Before confirming the shortest way from materials storage centers to disaster relief centers, first of all, we need to confirm whether the disaster relief centers stand and road information after the disaster. In recent years, the state and local governments pay high attentions to and try best to prevent emergencies, creating emergency plans and emergency relief centers so as to deal with emergency logistics in case of any disaster. If any disaster occurs, we can get road information via many ways and confirm which roads are available. After confirming the disaster relief centers sites and roads, we can calculate the shortest way from materials storage centers to the disaster relief center.

\section{Punishment Coefficient for Failure to Meet Materials Demand at Disaster Relief Centers}

Due to the differences in disaster loss (as house damages, the injured proportion) and people proportion (as more children or the old at some areas), the disaster relief centers will distribute different materials. For the areas where there are many children or old people, it will be urgent to need disaster relief materials as tents and foods, so if there are inadequate materials, it will cause higher loss, and the punishment coefficient will be bigger.

\section{CONCLUSION}

Based on emergency logistics researches by scholars at home and abroad, this article analyzes characteristics of emergency logistics, showing the differences between emergency logistics and general vehicle scheduling, and designs an emergency vehicle scheduling system. In the end, it proposes key problems existing in the emergency vehicle scheduling in order to put a solid foundation for the further research on emergency logistics.

\section{REFERENCES}

[1] Wang Feng, Jiang Yuhong, Wangjin, Emergency Logistics [D]. China Logistics Publishing House, 2007. (in Chinese)

[2] Heung-Suk Hwang. A Food Distribution Model for Famine Relief. Computer \& Industrial Engineering[J]. 1999: 335-338. (in Chinese)

[3] He Jianmin, Liu Chunlin, et al, Emergency Management and Emergency Systems: Location Selection, Scheduling and Algorithm [M] Beijing: Science Press, 2005. (in Chinese)

[4] Gai Hui, Study on Emergency Materials Vehicle Scheduling Models [D]. Thesis for Master's Degree at Changsha University of Science \& Technology, 2008. (in Chinese)

[5] Chen Jie, Genetic Algorithm-based Emergency Materials Transport Scheduling, Thesis for Master's Degree at Harbin Institute of Technology, 2006. (in Chinese)

[6] Miu Cheng, Study on Optimized Emergency Logistics for Sudden Accidents [D] Thesis for Dr. at Tongji University, 2007. (in Chinese)

[7] Ji Lei, Chi Hong, et al, Emergency Management over Sudden Accidents [M]. Higher Education Press, 2005. (in Chinese) 